\title{
More endemic birds occur in regions with stable climate, more plant species and high altitudinal range in China
}

\author{
Gang Feng ${ }^{1 *} \mathbb{D}$, Xiongwei Huang ${ }^{2}$, Lingfeng $\mathrm{MaO}^{3}, \mathrm{Na} \mathrm{Wang}^{1}$, Xueting Yang ${ }^{1}$ and Yanping Wang ${ }^{4}$
}

\begin{abstract}
Background: Geographical distribution of endemic species and its multiple scale drivers are an important topic in biodiversity conservation, because these species are especially vulnerable to climate change and habitat degradation, and therefore have high conservation priority. Here, for the first time, we simultaneously linked glacial-interglacial climate change, contemporary climate, plant species richness and altitudinal range with endemic bird distribution in China.
\end{abstract}

Methods: Ordinary least squares models and simultaneous autoregressive models were used to assess the associations between endemic bird richness, endemic bird ratio and each explanatory variable. Structural Equation Models were also performed to test the direct and indirect effects of these variables on endemic bird richness and endemic bird ratio.

Results: Higher endemic bird richness and endemic bird ratio occurred in regions with stable glacial-interglacial temperature, i.e., southwest China. Plant species richness and altitudinal range were also positively correlated with endemic bird richness and endemic bird ratio. Glacial-interglacial temperature change, contemporary precipitation, plant species richness and altitudinal range were all included in the best combination of variables for endemic bird richness. Importantly, glacial-interglacial temperature change had strong direct effects on both endemic bird richness and endemic bird ratio, while plant species richness only had a direct effect on endemic bird richness.

Conclusions: Our results indicate that endemic birds in China concentrate in southwest regions where there are stable glacial-interglacial temperature, more plant species and larger altitudinal range. Notably, while stable climate has strong direct effects on both endemic bird richness and endemic bird ratio, plant species may affect endemic bird richness through its effect on overall bird species richness. Importantly, the recent anthropogenic activities have also significantly intensified in this region, which would pose huge challenge for biodiversity conservation in China.

Keywords: Anthropogenic activities, Biodiversity conservation, Endemic bird ratio, Endemic bird richness, Glacialinterglacial climate change

*Correspondence: qaufenggang@163.com

${ }^{1}$ Ministry of Education Key Laboratory of Ecology and Resource Use of the Mongolian Plateau \& Inner Mongolia Key Laboratory of Grassland Ecology, School of Ecology and Environment, Inner Mongolia University, Hohhot 010021, China

Full list of author information is available at the end of the article

\section{Background}

Multiple-scale drivers and patterns of geographical distribution of endemic species are an important topic in conservation biogeography, because these species are particularly vulnerable to climate change and habitat degradation (Myers et al. 2000; Orme et al. 2005; Wu et al. 2017). Many endemism distribution related hypotheses at multiple spatial and temporal scales have recently

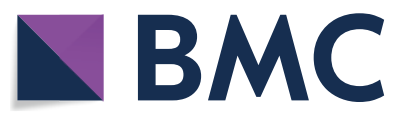

(c) The Author(s) 2020. This article is licensed under a Creative Commons Attribution 4.0 International License, which permits use, sharing, adaptation, distribution and reproduction in any medium or format, as long as you give appropriate credit to the original author(s) and the source, provide a link to the Creative Commons licence, and indicate if changes were made. The images or other third party material in this article are included in the article's Creative Commons licence, unless indicated otherwise in a credit line to the material. If material is not included in the article's Creative Commons licence and your intended use is not permitted by statutory regulation or exceeds the permitted use, you will need to obtain permission directly from the copyright holder. To view a copy of this licence, visit http://creativeco mmons.org/licenses/by/4.0/. The Creative Commons Public Domain Dedication waiver (http://creativecommons.org/publicdomain/ zero/1.0/) applies to the data made available in this article, unless otherwise stated in a credit line to the data. 
been widely tested, e.g., the orbitally forced species' range dynamics (ORD) hypothesis (Dynesius and Jansson 2000; Davies et al. 2011), the tropical niche conservatism hypothesis (Wiens and Donoghue 2004; Hawkins and DeVries 2009), the environmental heterogeneity hypothesis (Jetz et al. 2004; Stein et al. 2014), and the habitat diversity hypothesis (Young 2001; Lei et al. 2003).

The ORD hypothesis assumes that strong glacialinterglacial climate change would cause species range dynamics, which would then promote the extinction of small-ranged species and reduce paleoendemism, and also limit speciation and reduce neoendemism, resulting in a low endemic species richness (Dynesius and Jansson 2000; Feng et al. 2016). The tropic niche conservatism hypothesis suggests that the earth was historically dominated by tropical climate and many extant groups are originated in the tropics, which are difficult to survive in temperate region due to niche conservatism, therefore the tropics harbor high species richness as well as high endemic species richness (Wiens and Donoghue 2004; Hawkins and DeVries 2009; Feng et al. 2019).

Except for these climate-related hypotheses, higher environmental heterogeneity could also promote higher biodiversity by providing more niches, more refuges for adverse environment, and higher probability for diversification (Stein et al. 2014). Notably, altitudinal range, a widely used proxy for environment heterogeneity, may also reflect historical opportunities for allopatric speciation by providing past and present barriers (Jetz et al. 2004). Higher plant species richness is also linked with higher overall bird species richness and endemic bird richness, consistent with the hypothesis that plant diversity indicates habitat and food diversity for birds (Lei et al. 2003; Zhang et al. 2013; Liang et al. 2018).

China is one of the countries with richest biodiversity in the world, especially in the Northern Hemisphere, harboring about 33,000 vascular plant species and 1445 bird species (López-Pujol et al. 2006; Zheng 2017). The relatively stable glacial-interglacial climate compared with Europe and North America is one of the main reasons for its high plant diversity as well as high endemic plant species richness (Eiserhardt et al. 2015; Feng et al. 2019). The diverse vegetation types (including different types of forest and steppe) and the large mountains in southwest China are also important driving factors (López-Pujol et al. 2006; Feng et al. 2016). However, China also has the largest population and has experienced dramatic land use changes in the past centuries (He et al. 2013, 2015). Notably, the recently intensified anthropogenic activities in southwest China have promoted the high proportion of threatened plants in this region (Feng et al. 2017).

Previous studies suggest that glacial-interglacial climate change, altitudinal range and plant diversity might have left legacy on the distribution of endemic birds in China (Lei et al. 2003, 2015; Wu et al. 2017; Chen et al. 2019). However, so far no studies have simultaneously and quantitatively assessed the influence of these factors. Here, we linked the distribution of endemic bird richness and endemic bird ratio (endemic bird richness divided by all bird richness) in China with Last Glacial Maximumpresent climate change, contemporary climate, altitudinal range and plant species richness to test their associations. We predicted that there would be (1) more endemic birds in regions with stable glacial-interglacial climate, consistent with the ORD hypothesis; (2) more endemic birds in the current tropics, consistent with the tropic niche conservatism hypothesis; (3) more endemic birds in regions with higher altitudinal range, consistent with the environmental heterogeneity hypothesis; (4) more endemic birds in regions with higher plant species richness, consistent with the habitat/food diversity effects.

\section{Methods \\ Species distribution}

Distribution data of birds at prefecture city level in mainland China was compiled from published national, regional and provincial faunas, e.g., A Checklist on the Classification and Distribution of the Birds of China (Zheng 2017), Studies on Birds and Their Ecology in Northeast China (Gao 2006), The Avifauna of Yunnan China (Yang 1995; Yang and Yang 2004). There were descriptions about bird occurrence in prefecture cities in these faunas. And all the distribution information are based on the professional knowledge and field work of many experienced local ornithologists. Because there are still several provinces without published faunas, our bird (1209 species) distribution data only covered 22 provinces (including four direct-controlled municipalities), 214 prefecture cities. A list of bird species strictly endemic to China (93 species) was from $A$ Checklist on the Classification and Distribution of the Birds of China (Zheng 2017), and 56 species (Additional file 1: Table S1) occurred in our prefecture city level distribution data. Plant species richness in each prefecture city was compiled from the China Vascular Plant Distribution Database (Lu et al. 2018), which is based on plant distribution information from national, provincial and regional floras, as well as some herbarium specimens.

Although these political units based distribution data may have limited biological meaning, it is also widely used in endemism related studies, even in regions with better equal-area gridded data, e.g., endemic richness patterns in European countries (Essl et al. 2013a, b). Still, to overcome the potential bias of our faunas based species checklist, bird distribution data from GBIF (including ebird) and the National Specimen Information 
Infrastructure of China (including many herbarium specimens) was also used in this study. Specifically, we mapped these georeferenced point data on the prefecture city map of Chinese mainland. Richness of endemic species and overall species was then calculated for each prefecture city for the two different data sources (faunas based and georeferenced), respectively.

\section{Environmental variables}

Contemporary and Last Glacial Maximum climate variables, e.g., mean annual temperature (temperature) and mean annual precipitation (precipitation), were downloaded from WorldClim (Hijmans et al. 2005). Altitudinal range (the difference between the maximum and minimum value in each prefecture city) was calculated using a digital elevation model in the same source. Precipitation in Last Glacial Maximum and temperature in Last Glacial Maximum were the mean values of two models, i.e., the Community Climate System Model version 3 (Hijmans et al. 2005; Otto-Bliesner et al. 2006) and the Model for Interdisciplinary Research on Climate version 3.2 (Hasumi and Emori 2004). Glacial-interglacial anomaly in temperature and precipitation were then computed as the contemporary values minus the Last Glacial Maximum values. Although the area of the 214 cities ranged from 550 to $490,000 \mathrm{~km}^{2}$, its effects on both endemic bird richness (Pearson correlation $=0.06$ ) and endemic bird ratio (Pearson correlation $=0.04$ ) were not significant, so we did not include this variable.

\section{Statistical analyses}

Endemic bird richness was log transformed to get normal distributed residuals. All variables were then standardized (standard deviation $=1$ and mean $=0$ ) to make the regression coefficients comparable. Pearson correlations among all independent variables were calculated to check the multicollinearity. Ordinary least squares models were used to assess the associations between endemic bird richness, endemic bird ratio and each explanatory variable. Simultaneous autoregressive models were also used to account for the spatial autocorrelation of residuals. To find the combination of variables most associated with endemic bird richness and endemic bird ratio, multiple regression models were also computed using simultaneous autoregressive models.

Because plant species richness could also be affected by altitudinal range, temperature, precipitation, anomaly in temperature and precipitation, Structural Equation Models were used to test the direct and indirect effects of these variables on endemic bird richness and endemic bird ratio. Due to the high correlations between temperature and precipitation (0.84), and between temperature and anomaly in temperature $(-0.72$, Additional file 2 :
Table S2), we excluded temperature in the multiple variables analyses and Structural Equation Models. In terms of the two Structural Equation Models, the root-meansquare error of approximation was always less than 0.05 , and the comparative fit index was always larger than 0.9.

To test the potential effects of anthropogenic activities on endemic bird distribution, we also analyzed the historical change of population densities in the cities (the first quarter, i.e., 54 cities) with the highest endemic bird ratio. The dataset of population density was compiled from the History Database of the Global Environment (Goldewijk et al. 2011). All analyses were conducted in R (R Development Core Team 2016) using vegan (Oksanen et al. 2015), spdep (Bivand et al. 2015) and lavaan (Rosseel 2012) packages.

\section{Results}

Because the endemic richness/ratio patterns were similar for faunas and georeferenced based datasets, i.e., both endemic bird richness and endemic bird ratio showed higher values in southwest China (Fig. 1 and Additional file 3: Figure S1), we only presented the faunas based results for other analyses. Southwest China also has lower anomaly in temperature, higher plant species richness, and relatively larger altitudinal range (Fig. 1). Ordinary least squares models and simultaneous autoregressive models showed that the three variables most associated with endemic bird richness and endemic bird ratio were anomaly in temperature, plant species richness and altitudinal range (Fig. 2; Table 1). Notably, both endemic bird richness and endemic bird ratio decreased with higher glacial-interglacial anomaly in temperature, and increased with more plant species and higher altitudinal range (Fig. 2).

Multiple regression models showed that the combination of variables most associated with endemic bird richness included plant species richness, anomaly in temperature, mean annual precipitation and altitudinal range (Table 2), while the combination of variables most associated with endemic bird ratio included altitudinal range, anomaly in temperature and anomaly in precipitation (Table 2).

Structural Equation Models showed that anomaly in temperature had strong direct effects on both endemic bird richness and endemic bird ratio, while plant species richness only had significant effect on endemic bird richness (Fig. 3). Precipitation and altitudinal range could indirectly affect endemic bird richness through their effects on plant species richness, although their direct effects were not significant (Fig. 3). The population density in the 54 cities with the highest endemic bird ratio increased significantly in the past century, especially in the past 50 years (Fig. 4). 


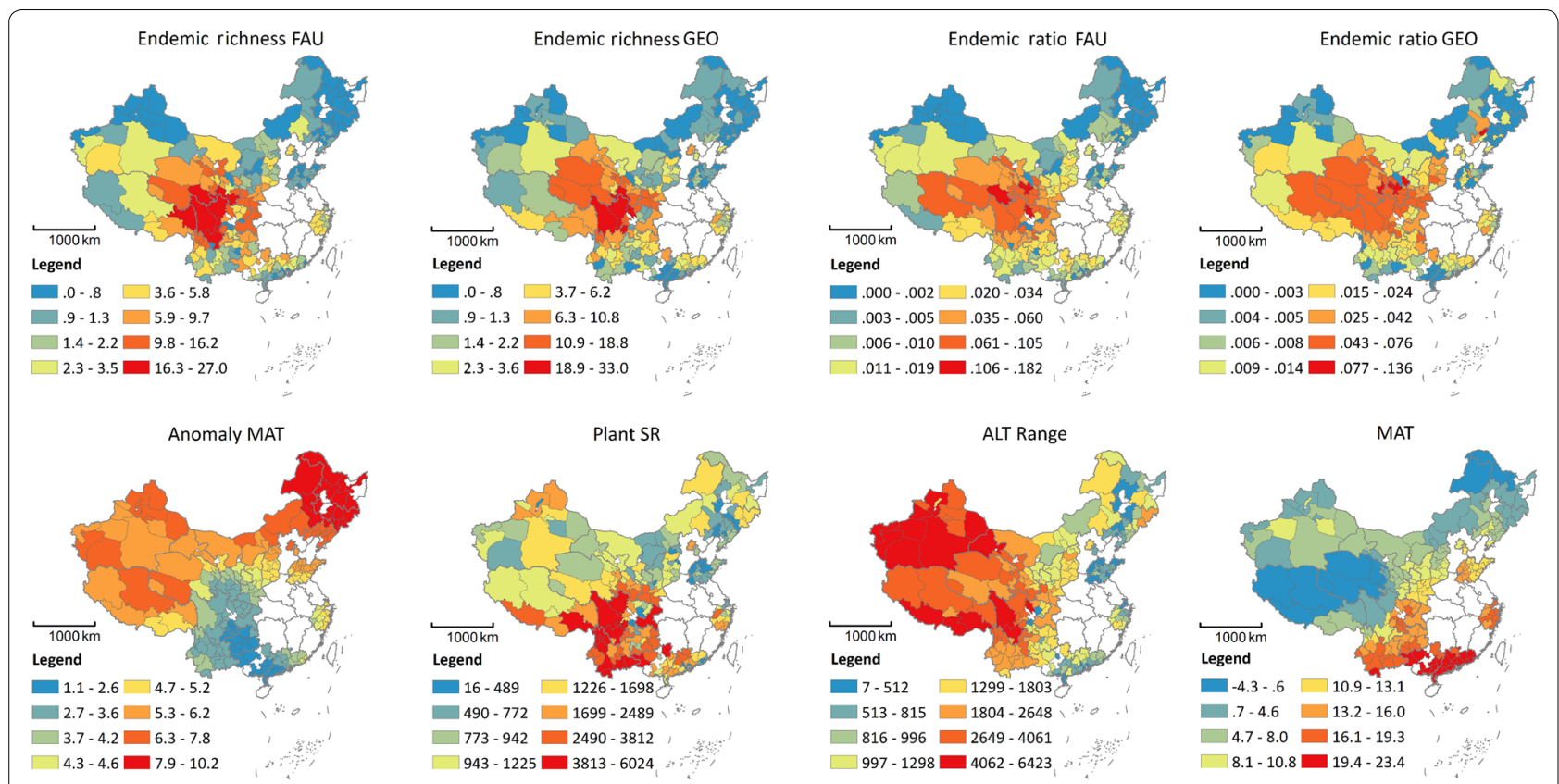

Fig. 1 Maps of faunas (FAU) based and georeferenced (GEO) endemic richness, endemic ratio, glacial-interglacial anomaly in MAT (Anomaly MAT), plant species richness (Plant SR), altitudinal range (ALT Range), and MAT. MAT mean annual temperature
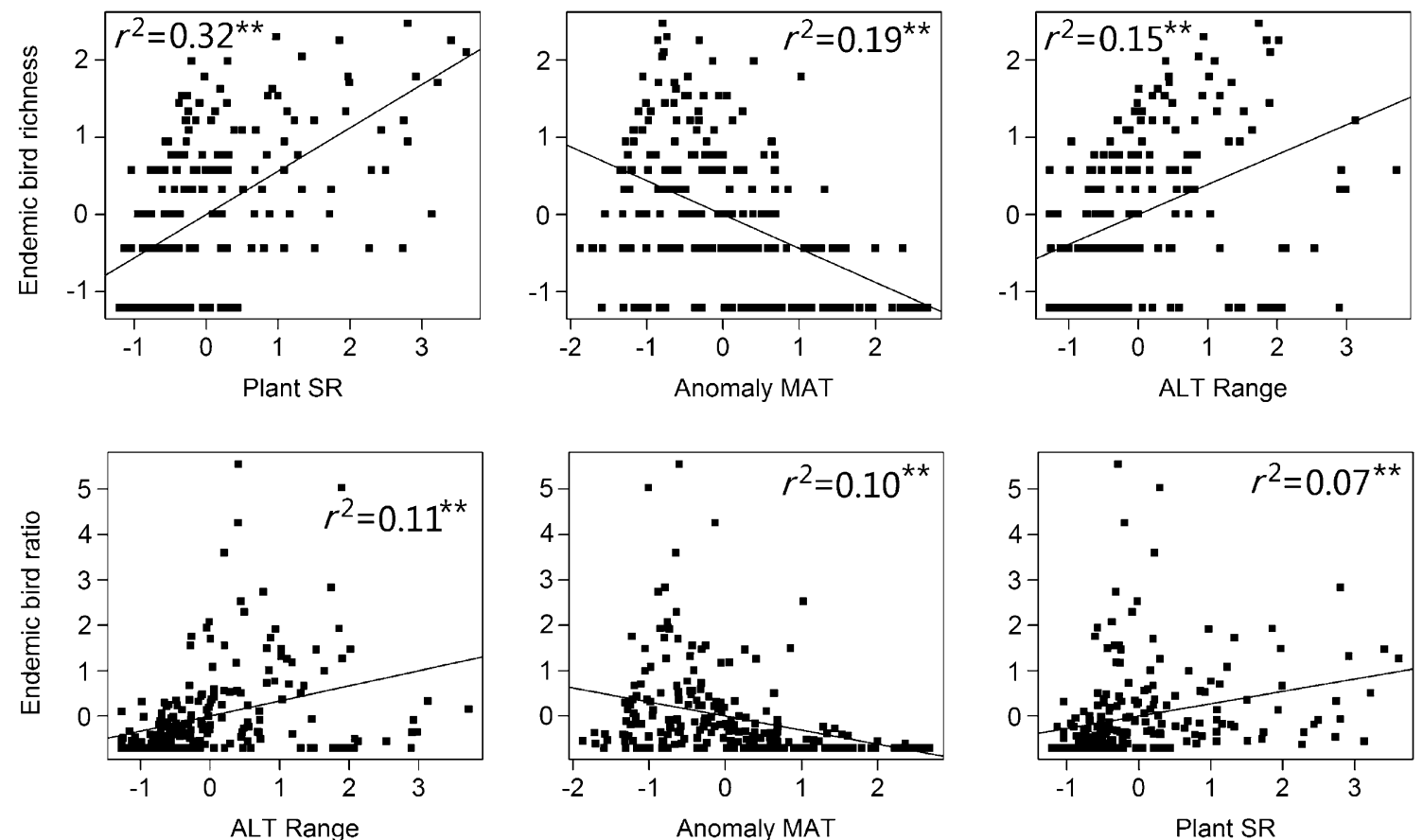

Fig. 2 Scatter plots of endemic bird richness, endemic bird ratio against their associated variables, plant species richness (Plant SR), altitudinal range (ALT Range), and glacial-interglacial anomaly in MAT (Anomaly MAT). MAT mean annual temperature. $r^{2}$ and standardized regression coefficients (the lines) of ordinary least squares models were listed 
Table 1 Results of single variable analyses by ordinary least squares models (ols) and simultaneous autoregressive models (sar)

\begin{tabular}{|c|c|c|c|c|c|c|c|c|}
\hline \multirow[t]{2}{*}{ Variable } & \multicolumn{4}{|c|}{ Endemic bird richness } & \multicolumn{4}{|c|}{ Endemic bird ratio } \\
\hline & $r_{\text {ols }}^{2}$ & Coef_ols & AIC_sar & $\overline{\text { Coef }_{\text {sar }}}$ & $r_{\text {_ols }}^{2}$ & Coef_ols & $A_{\text {IIC }}$ sar & Coef _sar $_{\text {sar }}$ \\
\hline MAT & 0 & 0 & 499 & $-0.25^{*}$ & 0.03 & $-0.17^{*}$ & 489 & $-0.35^{* *}$ \\
\hline MAP & 0.02 & 0.13 & 503 & 0.07 & 0 & -0.05 & 499 & -0.06 \\
\hline Anomaly MAT & 0.19 & $-0.44^{* *}$ & 498 & $-0.32^{* *}$ & 0.10 & $-0.31^{* *}$ & 497 & -0.19 \\
\hline Anomaly MAP & 0.02 & $0.16^{*}$ & 501 & 0.13 & 0.05 & $0.23^{* *}$ & 496 & 0.17 \\
\hline ALT Range & 0.15 & $0.39^{* *}$ & 471 & $0.45^{* *}$ & 0.11 & $0.33^{* *}$ & 488 & $0.27^{* *}$ \\
\hline Plant SR & 0.32 & $0.56^{* *}$ & 430 & $0.54^{* *}$ & 0.07 & $0.27^{* *}$ & 492 & $0.18^{* *}$ \\
\hline
\end{tabular}

MAT was mean annual temperature; MAP was mean annual precipitation; Anomaly MAT and Anomaly MAP were glacial-interglacial anomaly in MAT and MAP; ALT Range was altitudinal range; Plant SR was plant species richness. $r^{2}$ and coefficients (Coef) of ols, Akaike's information criterion (AIC) and Coef of sar were listed. ${ }^{*} p<0.05,{ }^{* *} p<0.01$

Table 2 Combinations of variables most associated with endemic bird richness and endemic bird ratio by simultaneous autoregressive models

\begin{tabular}{llllll}
\hline & \multicolumn{2}{l}{ Endemic bird richness } & & \multicolumn{2}{c}{ Endemic bird ratio } \\
\cline { 2 - 3 } & Coef & $w$ & & Coef & $\boldsymbol{w}$ \\
\hline MAP & $-0.26^{*}$ & 0.72 & & 0.42 \\
Anomaly MAT & $-0.30^{*}$ & 0.71 & & -0.20 & 0.62 \\
Anomaly MAP & & 0.28 & & 0.17 & 0.58 \\
ALT Range & 0.14 & 0.69 & & $0.27^{* *}$ & 0.92 \\
Plant SR & $0.49^{* *}$ & 1 & & 0.45 \\
Pseudo $r^{2}$ & 0.60 & & & 0.46 & \\
AIC & 424 & & & 486 & \\
\hline
\end{tabular}

Coefficients (Coef) of the variables included in the best combination, pseudo $r^{2}$ and AIC of the best combination were listed. The Akaike weight $(w)$ for each variable based on the full model sets was also listed. ${ }^{*} p<0.05,{ }^{* *} p<0.01$

\section{Discussion}

Being the first study simultaneously and quantitatively assessing the associations between Chinese endemic bird richness, endemic bird ratio and glacial-interglacial climate change, contemporary climate, altitudinal range and plant species richness, we found more endemic birds in regions with stable glacial-interglacial temperature, higher altitudinal range and more plant species, i.e., southwest China. More importantly, while plant species richness only directly affected endemic bird richness, glacial-interglacial anomaly in temperature had strong direct effects on both endemic bird richness and endemic bird ratio, emphasizing its important role in shaping the distribution of endemic birds in China. Notably, our results also showed these regions with high endemic bird

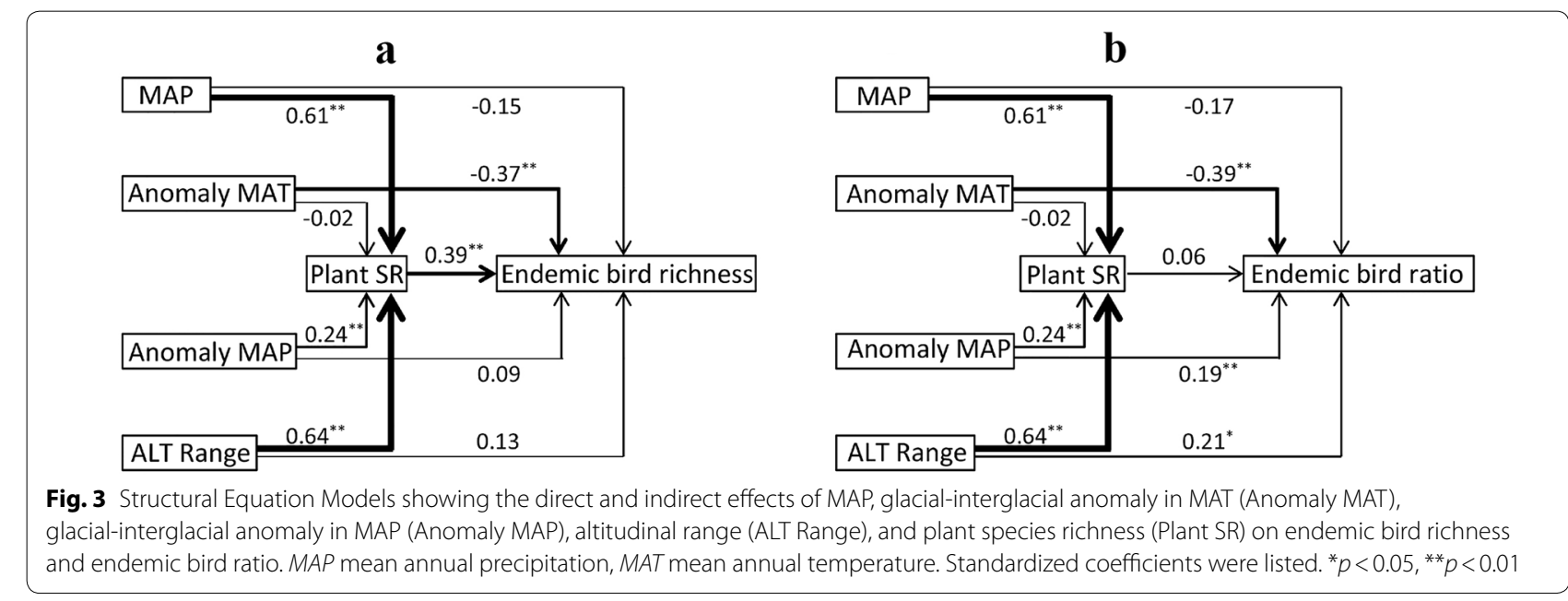




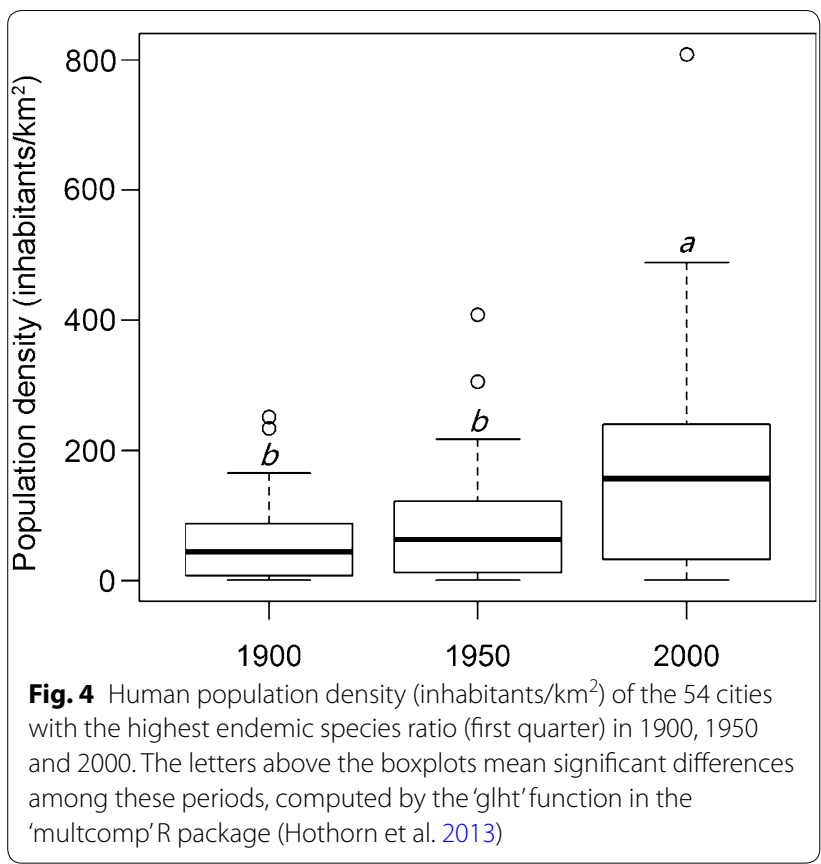

ratio have experienced intensified anthropogenic activities in the past decades.

\section{Stable glacial-interglacial temperature and more endemic birds}

Regions with stable glacial-interglacial climate could have higher speciation rate and lower extinction rate, which then promote higher richness of both neoendemics and paleoendemics (Fjeldså and Lovett 1997a, b; Dynesius and Jansson 2000). Supporting this hypothesis, paleoendemic plant species, neoendemic plant species, and the overall endemic plant species in China are concentrated in regions with stable glacial-interglacial climate, i.e., southwest China (Feng et al. 2016). In addition, previous studies about endemic bird richness in China also find that southwest China, including the Hengduan mountain and the western edge of Sichuan Basin, harbors more endemics, and suggest that the stable ancient climate may be one of the main reasons (Lei et al. 2003; Wu et al. 2017). Consistent with these studies, our results also showed more endemic birds in these regions. And more importantly, we found strong negative and direct effects of glacial-interglacial anomaly in temperature on both endemic bird richness and endemic bird ratio, i.e., there are more endemic birds with stable glacial-interglacial climate. Our findings provided strong and direct supplementary evidence for the role of stable glacial-interglacial climate in shaping the geographical distribution of endemic species, consistent with the orbitally forced species' range dynamics hypothesis (Dynesius and Jansson 2000; Davies et al. 2011).

\section{Higher altitudinal range and more endemic birds}

Except for the glacial-interglacial climate change, altitudinal range, a widely used proxy for environmental heterogeneity, has also been frequently linked with distribution of endemic species (Jetz et al. 2004; Sandel et al. 2011; Feng et al. 2016). Mountainous regions with larger altitudinal range could not only provide more ecological niches for species coexistence, but could also promote allopatric speciation and decrease extinction by forming geographical isolation and facilitating following climate changes (Jetz et al. 2004; Stein et al. 2014). Supporting these ideas, our results also showed that altitudinal range could indirectly affect endemic bird richness through its strong effect on plant species richness. More importantly, we also found direct and positive associations between altitudinal range and endemic bird ratio.

\section{Higher plant species richness and more endemic birds}

Higher plant species richness could affect bird species richness directly by providing food for herbivores and indirectly by providing diverse habitats for all groups (Zhang et al. 2013; Liang et al. 2018). The diverse habitats provided by high plant species richness in mountain region could also promote high endemic bird diversity (Lei et al. 2003). Consistent with these studies, our results also showed strong positive associations between plant species richness and endemic bird richness. However, the direct effect of plant species richness on endemic bird ratio was not significant, suggesting that high plant species richness may affect endemic bird richness through its effect on overall bird species richness.

\section{Conclusions}

In summary, by simultaneously linking multiple scale drivers with endemic bird richness and endemic bird ratio in China, our study suggests that the high endemic bird richness and endemic bird ratio in southwest China is codetermined by glacial-interglacial climate change, plant species richness and altitudinal range, especially for the glacial-interglacial temperature change, which has strong direct effects on both endemic bird richness and endemic bird ratio. Stable glacial-interglacial temperature in southwest China is one of the main drivers of its high values of overall biodiversity and endemic species richness, in terms of both plants and birds (López-Pujol et al. 2006; Feng et al. 2016; Wu et al. 2017). However, this region is also strongly affected by recent anthropogenic activities, which have significantly affected the distribution of threatened plants in China (Feng et al. 2017). Moreover, endemic bird species is especially vulnerable 
to these land use changes (Scharlemann et al. 2004; Maas et al. 2009), emphasizing the great challenge for the biodiversity conservation in southwest China.

\section{Supplementary information}

Supplementary information accompanies this paper at https://doi. org/10.1186/s40657-020-00203-y.

Additional file 1: Table S1. List of the 56 endemic species included in our study.

Additional file 2: Table S2. Correlations among explanatory variables.

Additional file 3: Figure S1. Scatter plots of faunas (FAU) based endemic richness/ratio against georeferenced (GEO) endemic richness/ratio.

\section{Acknowledgements}

Not applicable.

\section{Authors' contributions}

GF designed the study; XH, LM, NW, and XY collected the data; GF analyzed the data and wrote the paper; all authors contributed substantially to revisions. All authors read and approved the final manuscript.

\section{Funding}

This study was supported by the National Natural Science Foundation of China (No. 41861004 granted to GF, and 31870506 to ML), the Inner Mongolia Grassland Talent (12000-12102228 to GF), the Strategic Priority Research Program of the Chinese Academy of Sciences (No. XDB31000000 granted to ML), and Natural Science Foundation of Jiangsu Province (BK20181398 granted to $\mathrm{ML})$.

\section{Availability of data and materials}

The raw data that we collected are available upon request.

\section{Ethics approval and consent to participate}

Not applicable.

\section{Consent for publication}

Not applicable.

\section{Competing interests}

The authors declare that they have no competing interests.

\section{Author details}

${ }^{1}$ Ministry of Education Key Laboratory of Ecology and Resource Use of the Mongolian Plateau \& Inner Mongolia Key Laboratory of Grassland Ecology, School of Ecology and Environment, Inner Mongolia University, Hohhot 010021, China. ${ }^{2}$ Key Laboratory of Animal Ecology and Conservation Biology, Institute of Zoology, Chinese Academy of Sciences, Beijing 100101 China. ${ }^{3}$ Co-Innovation Center for Sustainable Forestry in Southern China, College of Biology and the Environment, Nanjing Forestry University, Nanjing 210037, China. ${ }^{4}$ Jiangsu Key Laboratory for Biodiversity and Biotechnology, College of Life Sciences, Nanjing Normal University, Nanjing 210023, China.

Received: 30 December 2019 Accepted: 16 May 2020

Published online: 22 May 2020

\section{References}

Bivand R, Altman M, Anselin L, Assunção R, Berke O, Bernat A, et al. spdep: Spatial dependence: weighting schemes, statistics and models. R package version 0.5-92. 2015. http://CRAN.Rproject.org/package=spdep.

Chen C, Zeng D, Zhao Y, Wu Y, Xu J, Wang Y. Correlates of extinction risk in Chinese endemic birds. Avian Res. 2019;10:8.
Davies TJ, Buckley LB, Grenyer R, Gittleman JL. The influence of past and present climate on the biogeography of modern mammal diversity. Philos $T$ Roy Soc B. 2011;366:2526-35.

Dynesius M, Jansson R. Evolutionary consequences of changes in species' geographical distributions driven by milankovitch climate oscillations. P Natl Acad Sci USA. 2000;97:9115-20.

Eiserhardt WL, Borchsenius F, Plum CM, Ordonez A, Svenning J-C. Climatedriven extinctions shape the phylogenetic structure of temperate tree floras. Ecol Lett. 2015;18:263-72.

Essl F, Rabitsch W, Dullinger S, Moser D, Milasowszky N. How well do we know species richness in a well-known continent? Temporal patterns of endemic and widespread species descriptions in the European fauna. Glob Ecol Biogeogr. 2013a;22:29-39.

Essl F, Moser D, Dirnböck T, Dullinger S, Milasowszky N, Winter M, et al. Native, alien, endemic, threatened, and extinct species diversity in European countries. Biol Conserv. 2013b;164:90-7.

Feng G, Mao L, Sandel B, Swenson NG, Svenning J-C. High plant endemism in China is partially linked to reduced glacial-interglacial climate change. J Biogeogr. 2016;43:145-54.

Feng G, Mao L, Benito BM, Swenson NG, Svenning J-C. Historical anthropogenic footprints in the distribution of threatened plants in China. Biol Conserv. 2017;210:3-8.

Feng G, Ma Z, Sandel B, Mao L, Normand S, Ordonez A, et al. Species and phylogenetic endemism in angiosperm trees across the Northern Hemisphere are jointly shaped by modern climate and glacial-interglacial climate change. Glob Ecol Biogeogr. 2019;28:1393-402.

Fjeldså J, Lovett JC. Biodiversity and environmental stability. Biodivers Conserv. 1997a;6:315-23.

Fjeldså J, Lovett JC. Geographical patterns of old and young species in African forest biota: the significance of specific montane areas as evolutionary centres. Biodivers Conserv. 1997b;6:325-46.

Gao W. Studies on Birds and Their Ecology in Northeast China. Beijing: Science Press; 2006 (in Chinese).

Goldewijk KK, Beusen A, van Drecht G, de Vos M. The HYDE 3.1 spatially explicit database of human-induced global land-use change over the past 12,000 years. Glob Ecol Biogeogr. 2011;20:73-86.

Hasumi H, Emori S. K-1 coupled gcm (miroc) description. Tokyo: Center for Climate System Research, University of Tokyo; 2004.

Hawkins BA, DeVries PJ. Tropical niche conservatism and the species richness gradient of North American butterflies. J Biogeogr. 2009;36:1698-711.

He F, Li S, Zhang X, Ge Q, Dai J. Comparisons of cropland area from multiple datasets over the past 300 years in the traditional cultivated region of China. J Geogr Sci. 2013;23:978-90.

He F, Li S, Zhang X. A spatially explicit reconstruction of forest cover in China over 1700-2000. Glob Planet Change. 2015;131:73-81.

Hijmans RJ, Cameron SE, Parra JL, Jones PG, Jarvis A. Very high resolution interpolated climate surfaces for global land areas. Int J Climatol. 2005;25:1965-78.

Jetz W, Rahbek C, Colwell RK. The coincidence of rarity and richness and the potential signature of history in centres of endemism. Ecol Lett. 2004;7:1180-91.

Lei F, Qu Y, Lu J, Liu Y, Yin Z. Conservation on diversity and distribution patterns of endemic birds in China. Biodivers Conserv. 2003;12:239-54.

Lei F, Qu Y, Song G, Alström A, Fjeldså J. The potential drivers in forming avian diversity hotspots in the East Himalaya Mountains of Southwest China. Integr Zool. 2015;10:171-81.

Liang C, Feng G, Si X, Mao L, Yang G, Svenning J-C, et al. Bird species richness is associated with phylogenetic relatedness, plant species richness, and altitudinal range in Inner Mongolia. Ecol Evol. 2018;8:53-8.

López-Pujol J, Zhang F, Ge S. Plant biodiversity in China: richly varied, endangered, and in need of conservation. Biodivers Conserv. 2006;15:3983-4026

Lu L, Mao L, Yang T, Ye J, Liu B, Li HL, et al. Evolutionary history of the angiosperm flora of China. Nature. 2018;554:234-8.

Maas B, Putra DD, Waltert M, Clough Y, Tscharntke T, Schulze CH. Six years of habitat modification in a tropical rainforest margin of Indonesia do not affect bird diversity but endemic forest species. Biol Conserv. 2009;142:2665-71.

Myers N, Mittermeier RA, Mittermeier CG, Da Fonseca GAB, Kent J. Biodiversity hotspots for conservation priorities. Nature. 2000;403:853-8. 
Oksanen J, Blanchet FG, Friendly M, Kindt R, Legendre P, Minchin PR, et al. vegan: Community ecology package. 2015. http://cran.r-project.org/ package $=$ vegan

Orme CDL, Davies RG, Burgess M, Eigenbrod F, Pickup N, Olson VA, et al. Global hotspots of species richness are not congruent with endemism or threat. Nature. 2005;36:1016-9.

Otto-Bliesner BL, Brady EC, Clauzet G, Tomas R, Levis S, Kothavala Z. Last glacial maximum and Holocene climate in CCSM3. J Clim. 2006;19:2526-44.

R Core Team. R: A language and environment for statistical computing. Vienna, Austria: R Foundation for Statistical Computing; 2016.

Rosseel Y. lavaan: an R package for structural equation modeling. J Stat Softw. 2012;48:1-36.

Sandel B, Arge L, Dalsgaard B, Davies RG, Gaston KJ, Sutherland WJ, et al. The influence of late quaternary climate-change velocity on species endemism. Science. 2011;334:660-4.

Scharlemann JPW, Green RE, Balmford A. Land-use trends in Endemic Bird Areas: global expansion of agriculture in areas of high conservation value. Glob Chang Biol. 2004;10:2046-51.

Stein A, Gerstner K, Kreft H. Environmental heterogeneity as a universal driver of species richness across taxa, biomes and spatial scales. Ecol Lett. 2014;17:866-80
Hothorn T, Bretz F, Westfall P. Package "multcomp". 2013. http://cran.stat.sfu.ca/ web/packages/multcomp/multcomp.pdf.

Wiens JJ, Donoghue MJ. Historical biogeography, ecology and species richness. Trends Ecol Evol. 2004;19:639-44.

Wu Y, DuBay SG, Colwell RK, Ran J, Lei F. Mobile hotspots and refugia of avian diversity in the mountains of south-west China under past and contemporary global climate change. J Biogeogr. 2017:44:615-26.

Yang L. The Avifauna of Yunnan China. Non-Passeriformes, vol. I. Kunming: Yunnan Science and Technology Press; 1995 (in Chinese).

Yang L, Yang X. The Avifauna of Yunnan China, vol. II. Passeriformes. Kunming: Yunnan Science and Technology Press; 2004 (in Chinese).

Young KA. Habitat diversity and species diversity: testing the competition hypothesis with juvenile salmonids. Oikos. 2001;95:87-93.

Zhang J, Kissling WD, He F. Local forest structure, climate and human disturbance determine regional distribution of boreal bird species richness in Alberta. Canada. J Biogeogr. 2013;40:1131-42.

Zheng GM. A checklist on the classification and distribution of the birds of China. Beijing: Science Press; 2017 (in Chinese).
Ready to submit your research? Choose BMC and benefit from:

- fast, convenient online submission

- thorough peer review by experienced researchers in your field

- rapid publication on acceptance

- support for research data, including large and complex data types

- gold Open Access which fosters wider collaboration and increased citations

- maximum visibility for your research: over 100M website views per year

At BMC, research is always in progress.

Learn more biomedcentral.com/submissions 